\title{
Optimalisasi Penggunaan Media Sosial untuk Perpustakaan
}

\author{
Oleh : Nuning Kurniasih* \\ Program Studi Ilmu Perpustakaan Fakultas Ilmu Komunikasi \\ Universitas Padjadjaran \\ Email: nuning.kurniasih@unpad.ac.id / nuningkurniasih@yahoo.com \\ Prosiding Makalah Seminar Nasional \\ "Komunikasi, Informasi dan Perpustakaan di Era Global" \\ Fikom Unpad, Jatinangor, 15 Juni 2016 \\ Halaman: 1-9
}

\begin{abstract}
Social media usage has become a lifestyle. As an information services provider, library has to adapt the current lifestyle. Nowadays, there are quite many libraries have employed social media although the utilization has not optimal yet. This paper describes the trend of social media usage for library, types of social media platform could be employed by library, and how to optimize social media usage for library. The optimal social media usage would support library in providing best services for its users.
\end{abstract}

Keywords: Social Media, Library Services

\begin{abstract}
ABSTRAK
Penggunaan media sosial saat ini sudah menjadi gaya hidup. Perpustakaan sebagai lembaga penyelenggara layanan informasi harus dapat menyesuaikan diri dengan hal ini. Saat ini telah banyak perpustakaan yang menggunakan media sosial, namun belum banyak perpustakaan yang dapat memanfaatkan media sosial tersebut secara optimal. Paper ini berusaha untuk menguraikan bagaimana trend penggunaan media sosial di perpustakaan, platform media sosial apa saja yang dapat dipergunakan di perpustakaan dan bagaimana optimalisasi penggunaan media sosial untuk perpustakaan. Penggunaan media sosial secara optimal dapat mendukung perpustakaan memberikan layanan yang terbaik kepada pemustaka.
\end{abstract}

Kata Kunci: Media Sosial, Layanan Perpustakaan

\section{Pendahuluan}

Sebagaimana kita ketahui bersama bahwa penetrasi penggunaan internet saat ini meningkat dengan pesat. Data dari We Are Social, sebuah perusahaan dari Agensi yang berpusat di Singapura merilis "Digital in 2016" yang menampilkan data penggunaan internet di 30 negara, termasuk Indonesia. Dari data tersebut dapat diketahui bahwa:

a. Dari 259,1 Juta penduduk Indonesia, 88,1 Juta atau 34\% adalah pengguna internet, 79 Juta atau 30\% diantaranya adalah pengguna internet aktif , 326,3 juta menggunakan koneksi mobile (atau 126\% jumlah penduduk, dihitung berdasarkan akses mobile, bukan uniqe users) dan 66 juta atau $25 \%$ diantaranya adalah pengguna aktif media sosial.

b. Rata-rata penggunaan internet melalui PC atau tablet adalah 4 jam sehari (sebanyak 42 juta), 3 jam sehari melalui telepon seluler (33 Juta), 2 jam sehari menggunakan media sosial (51 Juta) dan 2 jam sehari untuk menonton TV(22 juta).

c. Dari total pengguna internet, $48 \%$ menggunakan internet setiap hari, 35\% mengunakan paling tidak seminggu sekali, 12\% menggunakan internet paling tidak sebulan sekali dan 5\% menggunakan internet lebih dari 1 bulan. 
d. Penggunaan platform sosial mencakup : BBM (19\%), Facebook (15\%), WhatsApp (14\%), Facebook Messanger (13\%), Google+ (12\%), Line (12\%), Twitter (11\%), Instagram (10\%), Wechat (8\%) dan Pinterest(7\%).

(Kemp 2016)

Besarnya penggunaan media sosial di masyarakat menjadi tantangan sekaligus peluang bagi perpustakaan dalam menjalankan fungsinya yang harus selalu berorientasi kepada pemustaka.

Saat ini telah banyak perpustakaan yang menggunakan media sosial untuk mendukung layanannya. Namun demikian, masih banyak perpustakaan yang belum optimal menggunakan media sosial tersebut. Sebuah hasil survey di UK, USA dan India terhadap 497 responden menyebutkan bahwa lebih dari $70 \%$ perpustakaan telah menggunakan media sosial. Dari jumlah tersebut, $60 \%$ perpustakaan telah menggunakan media sosial tiga tahun atau lebih dan sekitar 30\% pustakawan meng-update media sosial setiap hari. Adapun media sosial yang paling banyak dipergunakan oleh perpustakaan adalah Facebook dan Twitter (Taylor and Francis 2014). Data ini menunjukkan bahwa meskipun sudah banyak perpustakaan yang mempergunakan media sosial sebagai bagian dari layanan yang diberikan kepada pemustaka/pengguna, namun media sosial ini belum optimal dipergunakan. Banyak perpustakaan yang memiliki akun media sosial, namun tidak disertai pengelolaan yang baik. Paper ini berusaha untuk menguraikan bagaimana trend penggunaan media sosial di perpustakaan, platform media sosial apa saja yang dapat dipergunakan di perpustakaan dan bagaimana optimalisasi penggunaan media sosial untuk perpustakaan.

\section{Trend Penggunaan Media Sosial di Perpustakaan}

Media sosial mengacu pada penggunaan platform media baru yang mensyaratkan adanya komponen dan saluran komunikasi publik yang ditandai dengan adanya aktivitas online. Media sosial mencakup struktur sosial dimana di dalamnya orang-orang dapat saling berinteraksi dan berkolaborasi antara satu dengan yang lainnya. Menurut Ron Jones, ada empat jenis media sosial, yaitu social news, social sharing, social networking dan social bookmaning. Lebih lanjut Jones menjelaskan bahwa social news menyedikan fitur berita dimana pembacanya dapat memilih dan memberi komentar pada berita tersebut. Berita yang mendapat pemilih terbanyak akan dipromosikan paling depan. Contoh dari Social News adalah Digg, Sphinn, Newsvine dan BallHype. Social sharing menyediakan fitur untuk membuat, mengunggah dan membagi foto dan video dengan orang lain. Contoh platformnya adalah Flickr, Snapfish, YouTube dan Jumpcut. Social networks memberi kesempatan kepada orangorang untuk saling terhubung antara satu dengan yang lainnya sehingga mereka dapat terus mengikuti update informasi satu dengan lainnya. Contoh jejaring sosial adalah Facebook, LinkedIn, MySpace dan Twitter. Sementara di dalam Social bookmarking kita dapat menemukan site bookmark dan informasi yang menarik. Kita dapat menyimpan bookmarks online dan mengaksesnya dari manapun atau membaginya dengan yang lain. Contohnya adalah Delicious, Faves, StumbleUpon, BlogMarks dan Diigo, Jones dalam (Kurniasih 2013)

Perpustakaan sendiri biasanya menggunakan media sosial sebagai media untuk melakukan promosi, baik mempromosikan koleksi ataupun layanan yang ditawarkan. Namun dengan perkembangan masyarakat digital yang nyaris tidak dapat lepas dari internet, media sosial tampaknya bisa dimanfaatkan lebih dari sekedar media promosi.

Dicky Sukmana, Chief Creative Panenmaya dalam sebuah bincang-bincang bersama detikNET berkelakar bahwa kebutuhan pokok masyarakat saat ini sudah bergeser dari sandang, pangan dan papan, menjadi sandang pangan dan chargeran sehingga tantangan hidup bukan lagi harta, tahta dan wanita, tetapi menjadi harta, tahta dan kuota (Rahman 2015). Kelakar ini tentunya bukan tanpa alasan. Saat ini banyak kita dengar seseorang berkata tidak dapat hidup tanpa internet, merasa stress ketika tidak terhubung dengan internet sehingga membawa gadget menjadi hal yang wajib. Ketika gadget lupa dibawa atau tertinggal, kekhawatiran bisa melebihi 
kekhawatiran ketika dompet atau yang lainnya tertinggal atau ketika soket listrik menentukan posisi duduk. Ini berarti perpustakaan saat ini berhadapan dengan sebagian besar generasi millennium, generasi yang aktif berselancar di dunia maya hampir 24 jam dalam sehari. Kondisi demikian memberi peluang kepada perpustakaan untuk menjadikan media sosial sebagai media komunikasi dua arah. Perpustakaan dapat berinteraksi dengan masyarakat melalui media sosial, menyampaikan informasi, memberikan pendidikan pemakai, menjawab pertanyaan hingga mengumpulkan umpan balik dari masyarakat serta membangun jaringan kerjasama dengan perpustakaan lainnya. Selain itu, perpustakaan juga dapat memanfaatkan media sosial untuk mendistribusikan konten berdasarkan jenisnya melalui platform yang sesuai. Adapun jenis-jenis platform media sosial akan di sampaikan pada bagian berikutnya.

Hasil survey Taylor dan Francis di UK, US dan India, menyebutkan bahwa tujuan perpustakaan menggunakan media sosial adalah seperti terlihat pada Bagan1.

\section{Bagan 1}

\section{Tujuan Penggunaan Media Sosial di Perpustakaan di UK, US dan India}

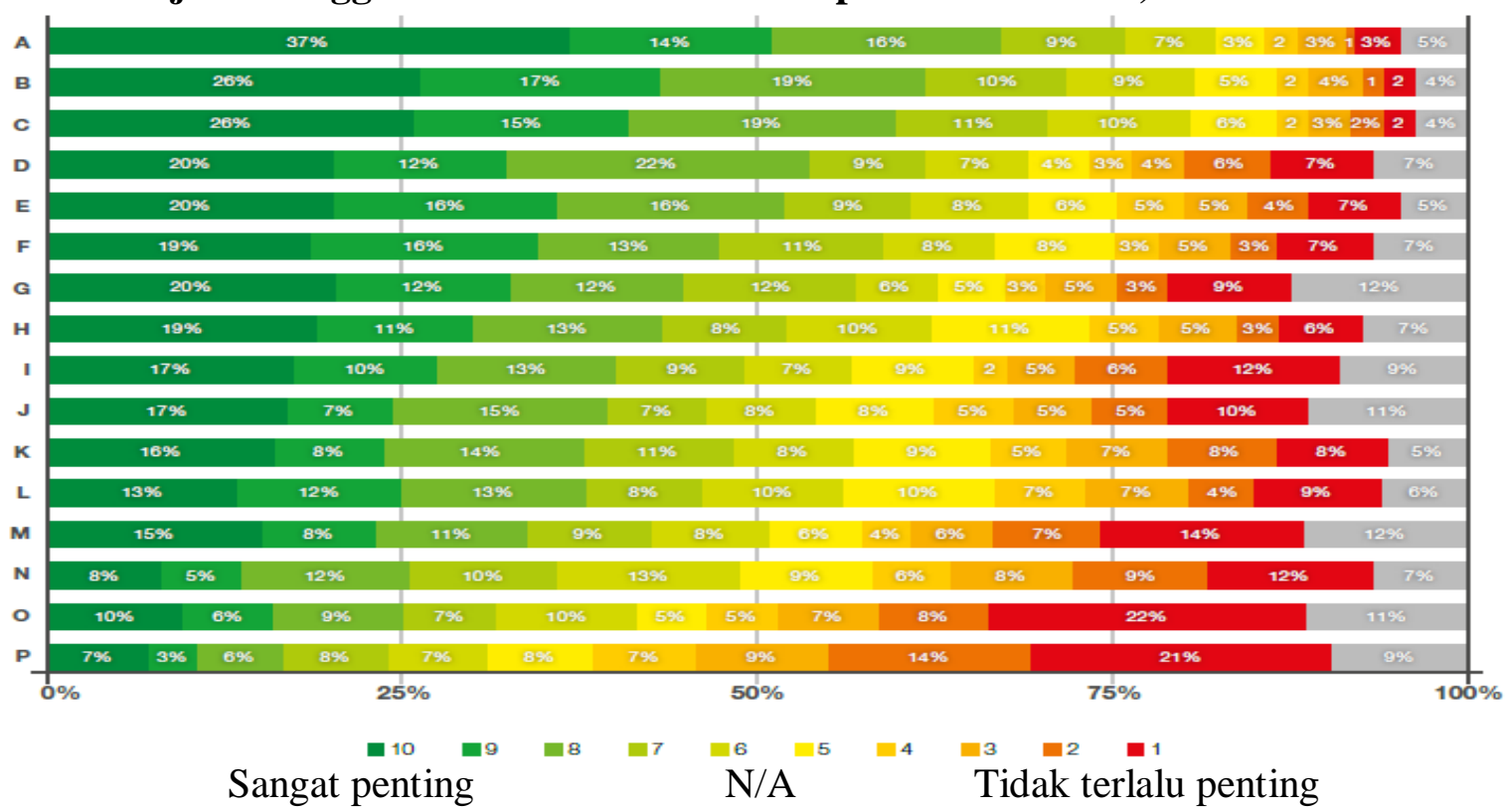

Sumber : (Taylor and Francis 2014)

Keterangan dari bagan tersebut adalah sebagai berikut :

A untuk mempromosikan kegiatan.

B untuk mempromosikan layanan perpustakaan

C untuk mempromosikan sumber informasi/koleksi yang ada di perpustakaan

D untuk meng-update renovasi perpustakaan

E untuk mempromosikan pengadaan baru

$\mathrm{F}$ untuk mempromosikan panduan perpustakaan, panduan pameran

$\mathrm{G}$ untuk menghubungkan dengan mahasiswa baru dengan universitas

$\mathrm{H}$ untuk bergabung dengan komunitas akademik

I untuk terhubung dengan komunitas yang lebih luas

J untuk terhubung dengan pembelajar jarak jauh

$\mathrm{K}$ sebagai alat layanan pelanggan yang dapat menampung complain, saran, permintaan dan umpan balik.

L untuk menandai informasi dengan subjek khusus.

M untuk terhubung dengan pelajar potensial

$\mathrm{N}$ sebagai alat pembelajaran yang mendukung literasi informasi, teknologi dan tips menulis (bukan berbasis berpustakaan)

O untuk mendukung mata pelajaran.

P sebagai alat penelitian untuk mencari dokumen dan studi resmi.

Dari bagan tersebut dapat terlihat bahwa promosi masih menjadi tujuan utama penggunaan media sosial di perpustakaan. 


\section{Macam-macam Platform Media Sosial}

Sebagaimana telah dikemukakan pada bagian sebelumnya, media sosial terdiri atas beberapa tipe dan masing-masing tipe tersebut mengacu pada fungsi dari masing-masing platform tersebut. Champeswar Mishra menyebutkan beberapa teknologi software sosial yang berasosiasi dengan layanan yang diberikannya tersebut sebagai berikut :

Tabel 1

Teknologi Software Sosial dan Layanannya

\begin{tabular}{|c|c|c|}
\hline Web 2.0 Web Sites & Web 2.0 Technology & Keterangan Layanan \\
\hline $\begin{array}{l}\text { Podcast Maker, Procast, } \\
\text { Odeo }\end{array}$ & Podcasting & $\begin{array}{l}\text { Penciptaan multimedia dan } \\
\text { sindikasi }\end{array}$ \\
\hline MediaWiki & Kolaborasi pengarang & Edit dan tag terbuka \\
\hline Flicker,Slide, Zoto & Manajemen foto dan citra & Akses foto dan tag terbuka \\
\hline $\begin{array}{l}\text { Delicious, Blinklist, } \\
\text { Stumbleupon }\end{array}$ & Tag sosial & Demokrasi ranking website \\
\hline Digg, Newsvine, Gabbr & Produksi berita bersama & Pengguna memilih berita \\
\hline $\begin{array}{l}\text { YouTube, Google, Video, } \\
\text { Metacafe }\end{array}$ & Koleksi video & Upload Video \\
\hline Blogger, WordPress & Bloging & $\begin{array}{l}\text { Kepengarangan dan } \\
\text { publikasi personal }\end{array}$ \\
\hline Joomla, Drupal & CMS & $\begin{array}{l}\text { Desain dan manajemen } \\
\text { web }\end{array}$ \\
\hline $\begin{array}{l}\text { MySpace, FaceBook, } \\
\text { Xanga }\end{array}$ & Jejaring sosial & $\begin{array}{l}\text { Terhubungnya orang per } \\
\text { orang dengan orang lain }\end{array}$ \\
\hline GoogleDocs, Rallypoint & Kolaborasi dalam menulis & $\begin{array}{l}\text { Memrosesan word secara } \\
\text { online }\end{array}$ \\
\hline $\begin{array}{l}\text { Google, Yahoo Answers, } \\
\text { IMDB }\end{array}$ & Mesin pencari & Pencarian target \\
\hline $\begin{array}{l}\text { Wayfaring, } \\
\text { Frappr,HouseMaps }\end{array}$ & Pemetaan & Berbagi peta pribadi \\
\hline
\end{tabular}

Sumber : (Mishra 200x)

Sementara itu menurut Alliance, jenis-jenis konten yang dapat dibagikan melalui media sosial antara lain:

1. Pinterest untuk brainstorming dan menciptakan infografis.

2. Twitter untuk terhubung ke blog dan menikmati serta membuat percakapan.

3. Google+ untuk berbagi foto dan tautan sebuah artikel.

4. Youtube untuk bebagi video, webinar dan tips.

5. Facebook untuk menampilkan gambar yang menarik termasuk panggilan untuk melakukan sebuah aksi.

6. Instagram untuk membuat kutipan dan meme.

(Alliance n.d.)

Lalu bagaimana dengan penggunaan platform media sosial di perpustakaan? Hasil survey Taylor dan Francis menunjukkan bahwa Facbook dan Twitter berada di urutan teratas popularitas penggunaan media sosial di perpustakaan. Selanjutnya diikuti oleh blogs, Google+, Instagram, Pinterest, Academic.edu, Flickr, ResearchGate, Slideshare dan Snapchat (Taylor and Francis 2014). 
Sementara itu menurut Mishra, kebutuhan perpustakaan pada media sosial terutama jejaring sosial adalah untuk :

1. Antisipasi timbal balik melalui kontribusi informasi yang berharga dengan harapan seseorang dapat memberikan dan menerima kembali bantuan dan informasi yang bernilai.

2. Peningkatan pengakuan dimana individu menginginkan pengakuan atas kontribusi mereka.

3. Rasa akan keberhasilan - kontributor percaya bahwa mereka memiliki beberapa efek pada pada lingkungan atau masyarakat.

4. Partisipasi pengguna- pengguna ingin lebih partisipasi dan kontribusi di web sosial. Lebih sosial dan kolaboratif. Jejaring sosial dapat memungkinkan pustakawan dan pengguna tidak hanya untuk berinteraksi, tetapi untuk berbagi dan mengubah sumber daya secara dinamis dalam media elektronik

5. Merangkul kepercayaan publik.

6. Terlibat dalam perubahan-perubahan yang cepat dan telah terlihat sejak dekade terakhir

7. Inovatif bersama- Ini didasarkan pada perpustakaan sebagai sebuah layanan komunitas yang memahami bahwa masyarakat berubah, perpustakaan tidak hanya mengubah masyarakat, tetapi juga mengubah perpustakaan.

8. Pergerakan open access - membuat koleksi tersedia secara terbuka, personal, interaktif, dan mendukung penciptaan, edit, komentar, bookmark, penilaian, tag, dll, oleh pengguna.

9. Tersedianya multimedia.

Sumber : (Mishra 200x)

Untuk memenuhi kebutuhan tersebut kemudian Mishra membagi kegiatan pustakawan di media sosial menjadi tiga kegiatan utama, yaitu untuk mengkomunikasikan informasi, mendistribusikan pengetahuan dan untuk mengorganisasikan pengetahuan (Mishra 200x).

Dalam mengkomunikasi informasi, pustakawan secara konsisten terhubung dan berinteraksi dengan seluruh pihak yang berkepentingan dengan membangun iklim kolaborasi online. Adapun platform yang dapat digunakan untuk ini antara lain Facebook, Twitter, LinkedIN, MySpace,Ning, blog, IM, seperti WhatsApps, LINE, Meebo, dll,

Distribusi informasi merupakan kegiatan berbagi informasi. Platform yang dapat digunakan untuk distribusi informasi antara lain Flicker, YouTube, TeacherTube (Youtube untuk guru, orang tua, instruktur perpustakaan), Second Life (perpustakaan virtual), Wikipedia, PBWiki (host wiki bisnis dan pendidikan), Footnote (dokumen sejarah asli), CommunityWalk (geografis), SlideShare, Digg (fungsi blog), StumbleUpon (pencarian channel), Daft Doggy (membuat tour web).

Pengorganisasian pengetahuan didasarkan pada informasi atau pengetahuan yang dapat diakses melalui teknologi media sosial. Adapun platform yang dapat digunakan antara lain aNobii untuk membantu pencinta buku berbagi review dan rekomendasi serta merencanakan waktu untuk berdiskusi bersama, Del,icio merupakan media bookmark yang dapat membuat direktori sesuai kebutuhan, Netvibes untuk mebuat public page yang dapat dilihat oleh semua orang, Connotea merupakan media referensi (layanannya telah berhenti pada 12 Maret 2013), LibraryThing merupakan jejaring katalog yang dapat menghubungkan perpustakaan dengan Amazon, Library of Congress, dan lebih dari 200 perpustakaan di dunia, lib.rario.us merupakan site sosial pengkatalogan.

Perpustakaan dapat memilih platform media sosial yang sesuai dengan tujuan perpustakaan menggunakan media sosial dengan tetap mempertimbangkan target audiennya. Dalam hal ini, perlu dilakukan kajian terlebih dahulu jenis platform yang banyak dipergunakan oleh target audien perpustakaan agar informasi yang disajian di dalam media sosial dapat sampai kepada target audien. 


\section{Manfaat Penggunaan Media Sosial oleh Perpustakaan}

Manfaat penggunaan media sosial oleh perpustakaan antara lain :

1. Dapat meraih target audien yang lebih luas dengan biaya yang murah.

2. Meningkatkan interaksi dengan masyarakat.

3. Dapat meningkatkan pengguna perpustakaan melalui kegiatan promosi di media sosial.

4. Dapat meningkatkan kolaborasi dengan berbagai pihak sehingga layanan perpustakaan dapat lebih kuat.

5. Meningkatkan partisipasi masyarakat dalam membangun perpustakaan yang lebih baik.

6. Menghemat waktu dan biaya penyebaran informasi.

7. Memberikan akses layanan perpustakaan yang lebih luas dan cepat.

8. Mendapatkan umpan balik secara langsung lebih cepat.

9. Membantu dalam meningkatkan citra perpustakaan/menjaga reputasi perpustakaan.

\section{Optimalisasi Penggunaan Media Sosial oleh Perpustakaan}

Untuk mengoptimalkan penggunaan media sosial oleh perpustakaan, perlu dilakukan langkah-langkah sebagai berikut :

1. Dukungan manajemen

Perlu ada komitmen dari lembaga, terutama manajemen dalam mendukung perubahan pola komunikasi dan budaya organisasi yang sesuai dengan karakteristik dunia maya terutama di media sosial. Ketika perpustakaan memutuskan untuk bergabung di media sosial, perlu dipahami ada pergeseran pola komunikasi. Komunikasi lebih terbuka secara horizontal. Kemudian budaya organisasi seperti jam layanan perpustakaan yang lebih fleksibel untuk layanan di media sosial.

2. Kualifikasi Pustakawan

Pemberian layanan melalui media sosial memerlukan kemampuan khusus dari pustakawan, antara lain kemampuan memposting sebuah informasi sesuai dengan karakter media sosial yang dipilih, berkomunikasi secara interaltif dengan follower, meyakinkan follower atas segala informasi yang dibagikan melalui media sosial, menjaga reputasi perpustakaan, pemahaman pada hak cipta, dll. Perlu diberikan pelatihan kepada pustakawan yang diberikan tugas mengurus media sosial.

3. Orientasi pengguna. Perpustakaan perlu memahami harapan pengguna ketika pengguna bergabung dengan akun media sosial perpustakaan. Harapan tersebut antara lain adalah bahwa pengguna dapat lebih kritis, perpustakaan lebih terbuka dan memberikan respon lebih cepat daripada layanan offline.

4. Sumber informasi. Media sosial mempermudah perpustakaan menyebarkan informasi. Namun demikian perlu diperhatikan hal-hal yang berkaitan dengan etika penyebaran informasi antara lain berkaitan dengan privacy dan hak atas kekayaan intelektual (HAKI) atau hak cipta.

5. Aktivitas di Media Sosial. Banyak perpustakaan memiliki akun media sosial dan banyak juga yang telah memposting informasi secara rutin, namun apakah posting-an tersebut dibaca atau mendapat respon dari follower? Diperlukan strategi agar setiap informasi yang diposting dapat dipahami dan mendapat perhatian dari follower.

Gambar 1 menjelaskan bagaimana perbedaan karakter media sosial dengan kopi. Perbedaan karakteristik media sosial ini perlu dipahami oleh pustakawan agar pustakawan dapat memposting sebuah informasi yang sesuai dengan platform media sosial. Sebagai contoh, ketika pepustakaan memilih Facebook dan Twitter, maka konten yang dibagikan melalui kedua media sosial tersebut bisa sama dengan kemasan pesan yang berbeda.

Dari gambar 1 dapat terlihat, bahwa pesan yang disampaikan dalam Facebook dapat berupa pesan seperti "I like coffee", atau untuk sebuah perpustakaan dapat memuat pesan:

"Saat ini telah berlangsung Seminar Ilmu Komunikasi dan Ilmu Perpustakaan di Perpustakaan Fikom Unpad”. 
Untuk kemasan pesan di twitter Marven mencontohkan "I am drinking \#cofee", ada hastag yang dipergunakan pada penekanan pesan, sehingga untuk pesan yang sama di Twitter dapat disampaikan sebagai berikut:

"Saat ini telah berlangsung \#Seminar \#IlmuKomunikasi dan \#IlmuPerpustakaan di @PerpustakaanFikomUnpad".

Lambang@menunjukkan bahwa twit tersebut di-mention ke akun Perpustakaan Fikom Unpad.

Gambar 1

Penjelasan Perbedaan Karakter Media Sosial dengan Kopi oleh Maven

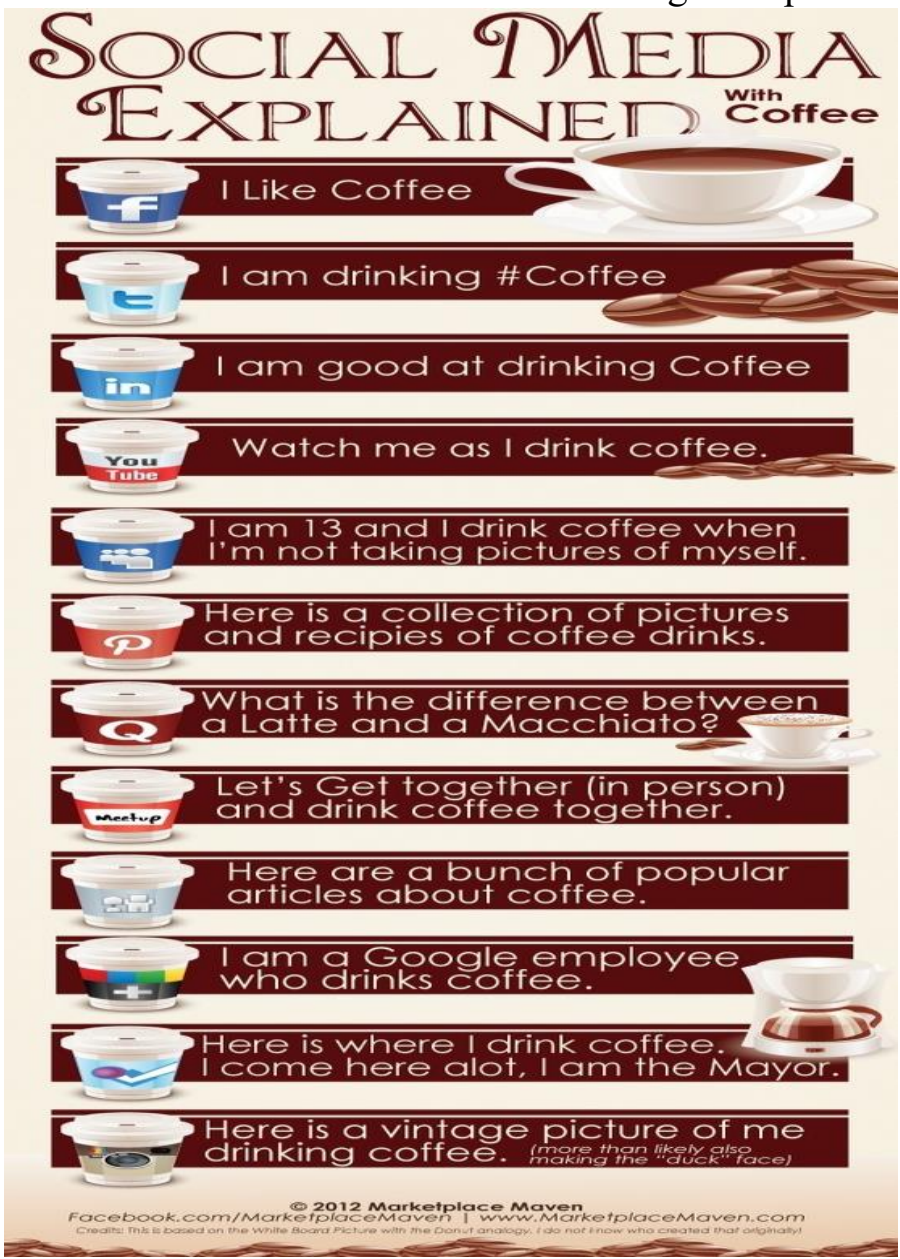

(Maven 2012)

\section{Beberapa Contoh Cara Posting Informasi di Media Sosial}

1. Cara posting di Youtube

Apabila pustakawan ingin memposting video lebih dari 1 menit, maka platform yang dapat dipergunakan adalah Youtube.

a. Upload video

b. Beri judul yang dapat menggambarkan isi video tersebut dengan maksimal 70 karakter.

c. Pilih Thumbnail yang menarik dan sesuai isi video agar audien mau membuka video tersebut.

d. Tuliskan deskripsi tentang video secara singkat.

e. Beri tag/Keyword yang dapat memandu pencari video sampai ke video tersebut.

f. Setting privasi, subscription, like dan komentar.

2. Cara posting di Facebook 
Memposting informasi atau foto di Facebook lebih fleksibel karena pustakawan dapat menulis informasi dengan panjang dan posting foto dalam jumlah banyak dalam sekali unggah. Namun demikian perlu diperhatikan :
a. Postinglah informasi yang bernilai.
b. Apabila akan memposting tautan, berilah judul tautan tersebut,
c. Resolusi terbaik untuk memposting foto di facebook adalah 800x600
d. Berikan respon kepada komentator.

3. Cara Posting di Twitter

a. Jumlah maksimal setiap posting di twitter adalah 140 karakter.

b. Apabila informasi yang akan disampaikan melebihi 140 karakter, buatlah butir-butir point dengan didahului mentweet judul atau tema tentang butir-butir tersebut.

c. Apabila akan mempergunakan singkatan kata, gunakan singkatan umum yang telah diketahui oleh publik. Jangan membuat singkatan yang tidak dapat dimengerti atau mebuat bingung follower.

d. Apabila akan menampilkan link, beri judul link dan gunakan penyingkat link.

e. Mention akun yang dituju apabila twit tersebut ditujukan kepada orang tertentu.

f. Retweet tweet yang diperlukan atau dianggap penting.

g. Dapat memposting foto.

h. Untuk menggunggah video streaming, gunakan Periscope.

4. Cara Posting di Pinterest

Pinterest adalah pinboard virtual yang berisi foto atau gambar yang dimasukkan ke dalam kategori-kategori, misalnya perpustakaan. Ada beberapa hal yang perlu diperhatikan ketika kita akan memposting foto atau gambar ke dalam Pinterset, antara lain :

a. Tidak memposting foto orang, karena lebih pada gambar atau foto berupa infografis.

b. Latar gambar seminimal mungkin.

c. Menggunakan aneka warna dalam gambar.

d. Orientasi gambar portrait.

5. Cara memposting di Google+

a. Menentukan Headline tidak lebih dari 60 karakter.

b. Menambahkan tautan ke dalam web.

c. Tag orang atau merek.

d. Ada trending topic

e. Gunakan hastag

f. Tambahkan foto.

g. Berinteraksi dengan komentator.

6. Cara memposting di Instagram

a. Instagram adalah platform media sosial untuk berbagi cerita melalui foto atau video.

b. Durasi video untuk awalnya hanya 15 detik, namun sekarang menjadi 1 menit.

c. Gunakan filter yang disediakan oleh Instagram.

d. Gunakan hastag

e. Gunakan repost atau regram untuk memposting foto atau film milik orang lain.

f. Berinteraksi dengan komentator.

\section{Asas Pemanfaatan Media Sosial}

Pedoman Pemanfaatan Media Sosial Instansi Pemerintah yang dikeluarkan oleh Menteri Pendayagunaan Aparatur Negara Dan Reformasi Birokrasi (PAN-RB) RI menyebutkan 9 asas media sosial yaitu faktual, dapat diakses dengan mudah dan diketahui oleh siapa saja, kapan 
saja, di mana, mendorong keikutsertaan dan masyarakat, interaktif, harmonis, etis, kesetaraan, antara instansi pemerintah dan pemangku kepentingan, professional dan akuntabel (Menteri Pendayagunaan Aparatur Negara dan Reformasi Birokrasi RI (PAN-RB) 2012). Dengan demikian seluruh instansi pemerintah, termasuk perpustakaan yang berada di bawah lembaga pemerintah harus berpedoman pada asas yang ditetapkan oleh MENPAN-RB tersebut di dalam mengelola media sosialnya.

\section{Penutup}

Pengelolaan media sosial oleh perpustakaan harus tertencana dengan baik. Untuk dapat mempergunakan media sosial dengan optimal, perpustakaan perlu memahami jenis dan karakteristik dari masing-masing media sosial. Pemahaman terhadap jenis dan karakteristik media sosial ini akan membawa perpustakaan mampu mengidentifikasi jenis konten yang dapat dibagikan sesuai platform media sosial yang dipilih. Perpustakaan dapat memilih satu atau beberapa jenis media sosial. Pemilihan jenis media sosial ini didasari kepada kebutuhan perpustakaan dan analisa jenis media sosial yang banyak dipergunakan oleh target pemustakanya. Hal terpenting yang harus disadari oleh perpustakaan, bahwa penggunaan media sosial membawa konsekuensi komunkasi yang lebih terbuka antara perpustakaan dengan masyarakat, pengguna dapat lebih kritis, perpustakaan diharapkan dapat memberikan respon lebih cepat daripada layanan offline. Dengan penggunaan media sosial diharapkan perpustakaan dapat lebih dekat dengan masyarakat dan dapat memberikan layanan terbaiknya.

Mengakhiri tulisan ini saya ingin mengutip apa yang disampaikan oleh Ronn Torossian dan Karen Kelly "Share what you know. Stay informed and constantly build knowledge of your industry so your insight, wisdom, and ideas are fresh. People will want to hear what you have to say; that's how you become a thought leader" (Torossian and Kelly 2011, 253). Media sosial akan menjadi dokumentasi online bagi setiap pengetahuan yang Anda berikan dan menjadi sumber inspirasi bagi orang lain.

\section{Daftar Pustaka}

Alliance, Quick. n.d. Types of Content to Share on Social Media. Accessed September 29, 2015. www.quickAlliance.com.

Kemp, Simon. 2016. Digital in 2016: We Are Social's Compendium of Global Digital, Socail and Mobile Data Trends and Statistics. Special Report, Singapore: wearesocialsg.

Kurniasih, Nuning. 2013. "Penggunaan Media Sosial bagi Humas di Lembaga Pemerintah." Forum Kehumasan Kota Tangerang. Bogor: Pemda Tangerang, September 26.

Maven, Marketplace. 2012. Social Media Explained with Coffee. Accessed September 29, 2015. www.facebook.com/marketplacemoven.

Menteri Pendayagunaan Aparatur Negara dan Reformasi Birokrasi RI (PAN-RB). 2012. "Pedoman Pemanfaatan Media Sosial Instansi Pemerintah." Peraturan Menteri Pendayagunaan Aparatur Negara dan Birokrasi RI No. 83 Tahun 2012. Jakarta: KemenPAN-RB, Desember 28.

Mishra, Champeswar. 200x. Social Networking Technologies (SITs) in Digital Environment: Accessed September 29, 2015.

http://eprints.rclis.org/16844/1/Social\%20networking\%20in\%20Library.pdf.

Pangarepan, Semuel A. 2015. Pengguna Internet Indonesia Tahun 2014, Sebanyak 88, 1 Juta $(34,9 \%) \ldots$. Maret 23. http://www.apjii.or.id/v2/read/content/infoterkini/301/pengguna-internet-indonesia-tahun-2014-sebanyak-88.html.

Rahman, Adi Fida. 2015. Tantangan di Era Digital: Harta, Tahta dan Kuota. September 29. Accessed September 29, 2015. 
http://inet.detik.com/read/2015/09/29/144939/3030842/1169/tantangan-di-era-digitalharta-tahta-dan-kuota.

Taylor, and Francis. 2014. Use of social media by the library current practices and future opportunities : A white paper. Oxford: Taylor \& Francis Group CC-BY-NC.

Torossian, Ronn, and Karen Kelly. 2011. For Immediate Release: Shape Minds, Build

Brands, and Deliver Results with Game-Changing Public Relations. Dallas, Texas: Benbella Books, Inc. 